\title{
Socio-economic and demographic determinants of childhood obesity prevalence in Greece: the GRECO (Greek Childhood Obesity) study
}

\author{
Paul Farajian ${ }^{1}$, Demosthenes B Panagiotakos ${ }^{2}$, Grigoris Risvas ${ }^{1}$, Konstantina Karasouli ${ }^{1}$, \\ Vasiliki Bountziouka ${ }^{2}$, Nikolaos Voutzourakis ${ }^{1}$ and Antonis Zampelas ${ }^{1, *}$ \\ 'Unit of Human Nutrition, Department of Food Science and Technology, Agricultural University of Athens, \\ lera Odos 75, Athens 1 1855, Greece: ${ }^{2}$ Department of Science of Dietetics-Nutrition, Harokopio University, \\ Athens, Greece
}

Submitted 23 May 2011: Final revision received 28 February 2012: Accepted 30 March 2012: First published online 25 May 2012

\begin{abstract}
Objective: Given the rapid increase in the prevalence of childhood obesity, identifying the sociodemographic influences on obesity status is important for planning and implementing effective prevention initiatives. However, this type of data is limited for Greek children. Therefore the aim of the present study was to identify possible sociodemographic factors associated with childhood obesity at the national level.

Design: Cross-sectional, population-based survey, carried out from October to May 2009.

Setting: Under the context of the GRECO (Greek Childhood Obesity) study, a nationwide sample of 2315 primary-school children.

Subjects: Children aged 10-12 years and their parents were voluntarily enrolled. Direct anthropometric measurements of the children were obtained and information on sociodemographic characteristics of the parents, as well as their self-reported values of body weight and height, were collected.

Results: Overweight and obesity prevalence was $29 \cdot 5 \%$ and $13 \cdot 1 \%$, respectively, among boys; $29 \cdot 5 \%$ and $9 \cdot 0 \%$, respectively, among girls. Multiple logistic regression analysis revealed that the most important sociodemographic predictors of childhood obesity were mother's age, parental BMI classification and father's type of occupation. More specifically, increased mother's age and normal BMI status of the parents seemed to have a protective effect on the likelihood of having an overweight/obese child. Additionally, the odds of a female child of being overweight/obese were reduced when the father's type of occupation tended to be less manual.

Conclusions: Anti-obesity health policy interventions have to address to the parents and promote their active involvement, to effectively confront the alarming magnitude of the paediatric obesity problem in Greece.
\end{abstract}

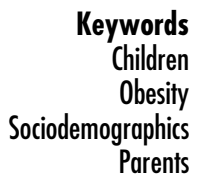

Obesity among children and adolescents is a growing public health problem. Previous cross-sectional studies conducted at local and regional level have reported that the prevalence of childhood obesity in Greece is among the highest in Europe ${ }^{(1)}$. According to Lobstein and Frelut ${ }^{(2)}$, who provided estimates of the prevalence of overweight/obesity in European countries, Greece was ranked fourth highest in obesity rate for 7-11-year-olds. Recently published results from the GRECO (Greek Childhood Obesity) study ${ }^{(3)}$, using nationally representative data from 10-12-year-old children and classification according to the International Obesity Taskforce cut-offs, verified the alarming magnitude of the paediatric obesity problem in all areas and regions of Greece, showing that the overall prevalence of overweight was $29 \cdot 5 \%$ and the prevalence of obesity was $11 \cdot 7 \%$, the highest ever reported in Greece.

The rapid increase in the prevalence of obesity in Greece during recent decades suggests that behavioural factors play a primary role, these being influenced by genetic, social and economic environments. Although obesity and particularly childhood obesity has a multifactorial nature, it has been shown that obesity status differs by social class and demographic factors ${ }^{(4,5)}$. However, a recent review by Shrewsbury and Wardle ${ }^{(5)}$ highlighted the fact that the relationship between childhood overweight/obesity and socio-economic status (SES) depends on the SES indicator used and that, consequently, it is important to identify the correct sociodemographic influences on obesity status in contemporary societies in order to design and implement 
effective prevention initiatives. Early prevention is more effective in managing the epidemic of obesity, in comparison with treating obesity in later life.

For the Greek childhood population, such data are scarce and sometimes conflicting. This is probably because they have predominantly been derived from regional studies with populations of different cultural backgrounds, or because of the different SES indicators used. Therefore the aim of the present paper, under the context of the GRECO study, was to identify and present for the first time several possible socio-economic and demographic factors that are associated with the very high childhood obesity rate at the national level.

\section{Methods}

\section{Sampling}

The GRECO study was carried out from October to May 2009. A stratified sampling scheme by age and sex group, based on the population distribution (National Statistical Services, 2001 census) in ten regions of the whole country (i.e. Attica, Macedonia, Peloponnisos, Sterea Ellada and Evia, Ipeiros, Thessalia, Thrace, Aegean islands, Ionian islands and Crete), was used to obtain a representative sample of 5000 children. The number of children had been pre-specified using statistical power calculations in order to achieve $85 \%$ power at $5 \%$ type I error when evaluating odds ratios equal to $1 \cdot 10$. Thus, using also the official catalogues provided by the regional directorates of primary education, a total of 5850 fifth and sixth grade schoolchildren from fourteen prefectures were invited for potential inclusion. The prefectures were grouped based on their population into 'large urban areas' with a population size greater than 1000000 inhabitants and 'urban and semi-urban areas' with a population size ranging from 10000 to 100000 inhabitants.

The number of schools that agreed to participate in the GRECO study was 117 from all over the country (fourteen prefectures). From the overall number of children who were invited to participate in the study, signed parental consent forms were obtained for 4965 children (corresponding to $84.9 \%$ participation rate). After checking the quality of the data obtained from the children and whether participants met the criteria for inclusion in the analysis, the resultant sample consisted of a total of 4786 children.

The research and all methods used in the study were approved by the Hellenic Ministry of Education (Department of Primary Education) as required by law for any study conducted in the school environment, during formal school hours, in Greece and the Agricultural University of Athens Research Committee. Before the initiation of measurements, an extended letter explaining the aims of the study was sent to the principal of each primary school. Additionally, each parent or guardian having a child in the contacted schools was provided with a letter explaining the aims of the study and a consent form. Those parents who agreed to participate in the study had to sign the consent form and send it back to the school.

\section{Children's anthropometry and obesity definition}

The measurements were conducted by investigators and staff of the Unit of Human Nutrition of the Agricultural University of Athens. All investigators followed a series of planning meetings and were trained in survey methods in training sessions that included practical experience in weighing and measuring techniques. Additionally, before the initiation of the study all investigators followed a twoweek practice period in primary schools that were not included in the final study sample in order to get familiarized with the procedures. All study sites used the same measuring equipment and procedures and in each class the team of investigators consisted of at least two people.

All measurements were performed during morning hours. Body weight was recorded to the nearest $100 \mathrm{~g}$ with the use of a digital scale (Tanita TBF 300, Japan) and with the child standing without shoes in light clothing. Standing height was measured using a portable stadiometer (Leicester height measure, Germany) to the nearest $0 \cdot 1 \mathrm{~cm}$ without shoes, with the head positioned in the Frankfort plane. BMI $\left(\mathrm{kg} / \mathrm{m}^{2}\right)$ was calculated by dividing body weight in kilograms by the square of standing height in metres. Waist and hip circumferences were measured to the nearest $0.1 \mathrm{~cm}$ with the use of a nonelastic tape (Seca, Germany) and with the child in standing position. Waist circumference was measured at the end of a gentle expiration after placing the measuring tape in a horizontal plane around the trunk, midway between the lower rib margin and the iliac crest. Obesity and overweight among children were calculated using the International Obesity Taskforce age- and genderspecific BMI cut-off criteria $^{(6)}$.

\section{Information obtained from parents/guardians}

Information on socio-economic and demographic characteristics, such as parents' age, current weight and height, years of education, annual family income, employment status, profession, type of occupation (manual workers (lower values) to executive/skilled workers (higher values)) and ownership of the residence, was collected via a questionnaire, attached to the consent form. Parents were also asked about the frequency of physical activity alone or together with their children, as well as the frequency of meals consumed with the whole family and the frequency of meals 'out of home'. Of the 4786 consent forms obtained, in the case of 2318 children we also obtained answered parental questionnaires. Parental obesity and overweight percentages were estimated from self-reported values of body weight and height: BMI was calculated and BMI measures were used to define adult (parental) obesity $\left(\mathrm{BMI} \geq 30 \cdot 0 \mathrm{~kg} / \mathrm{m}^{2}\right)$ and overweight 
$\left(\mathrm{BMI}=25 \cdot 0-29 \cdot 9 \mathrm{~kg} / \mathrm{m}^{2}\right)$ according to the WHO classification $^{(7)}$. The final number of parental questionnaires and families included in the analysis of the present paper was 2315 .

\section{Working sample}

In the present paper, data from 2315 children (45\% males and $55 \%$ females) for whom information about body weight and height was available, as well as the parents' questionnaire was completed, were used. The studied (working) sample can be considered representative of the overall study population (i.e. the 4786 children included for analysis in the GRECO study) with regard to age and BMI distributions $(P>0 \cdot 05)$, as differences in age group and BMI distributions were not evident (working sample $v$. overall sample: $24 \%$ v. $24 \%$ aged 10 years, $P=0 \cdot 79 ; 49 \%$ $v$. $48 \%$ aged 11 years, $P=0 \cdot 70 ; 27 \% v$. $28 \%$ aged 12 years, $P=0.56 ; 60 \% v$. $60 \%$ normal weight, $P=0.99 ; 29 \% v$. $29 \%$ overweight, $P=0.99 ; 11 \% v .11 \%$ obese, $P=0.99$ ). However, differences were revealed regarding gender $(P<0.05)$ and regional distribution $(P<0 \cdot 01)$. Specifically, the working sample comprised $45 \%$ boys ( $v .49 \%$ of the overall sample, $P=0.027)$ and $46 \%$ were from urban areas (v. $52 \%$ of the overall sample, $P=0.002$ ).

\section{Statistical analysis}

Continuous variables are presented as means and standard deviations, and categorical variables as frequencies and percentages. The normality of continuous variables was tested graphically according to P-P and Q-Q plots. Comparisons of continuous variables between groups were performed using the independent-samples $t$ test (for variables that were normally distributed). Associations between categorical variables were tested using the Pearson $\chi^{2}$ test (bivariate level), while correlations between continuous variables were performed using Pearson's $r$. Unadjusted (univariate; i.e. child's gender, child's age, mother's and father's age, mother's and father's type of occupation, mother's and father's educational level, place of residence, annual family income and parental BMI classification) and multiple logistic regression analysis were used to evaluate the main effect of several sociodemographic characteristics on childhood obesity prevalence. Variables included in the model of multiple logistic regression analysis were selected according to the results of unadjusted models (i.e. $P<0 \cdot 05$ ) and as such to avoid collinearity. Specifically, child's age and gender, mother's age, father's type of occupation, father's educational level, place of residence, annual family income and parental BMI classification were included in the final model. Results are presented as odds ratios and the corresponding $95 \%$ confidence intervals. The Hosmer-Lemeshow statistic was used to test the models' goodness-of-fit. All tested hypotheses were two-sided. $P<0.05$ was considered as statistically significant. The PASW Statistics 18 statistical software package was used for all calculations (SPSS Inc., Chicago, IL, USA).

\section{Results}

The mean age of the 2315 children with anthropometric measurements and information regarding sociodemographic factors of their parents was $10 \cdot 87$ (SD 0.73) years, with $54 \%$ and $46 \%$ coming from large urban and urban plus semiurban areas, respectively. In order to check for any bias regarding the data analysis of the sample of children used in the present study compared with the children for whom we did not obtain parental information, we compared the BMI of the two groups and found no differences $(P>0 \cdot 05)$.

The descriptive characteristics of the population and the prevalence of overweight and obesity according to gender are presented in Table 1 . In addition, comparisons of normal-weight and overweight/obese schoolchildren in relation to several sociodemographic factors and parental BMI classification are presented in Table 2 . Concerning the obesity status of the parents, $25 \cdot 5 \%, 55 \cdot 2 \%$ and $19 \cdot 3 \%$ of the fathers and $65 \cdot 3 \%, 26 \cdot 7 \%$ and $8 \cdot 0 \%$ of the mothers were classified as normal weight, overweight and obese, respectively. BMI of the mothers and fathers was positively correlated with $\mathrm{BMI}$ and waist circumference of the children, in both genders $(P<0 \cdot 001)$. Furthermore, no differences were observed in the prevalence of overweight, obesity or overweight/obesity combined in the overall sample and in both genders according to residence in large urban or urban plus semi-urban areas $(P>0.05$ for all).

Table 1 Descriptive characteristics of the population and prevalence of overweight and obesity according to gender: nationwide sample of primary-school children aged 10-12 years, GRECO (Greek Childhood Obesity) study, October-May 2009

\begin{tabular}{|c|c|c|c|c|c|c|}
\hline & \multicolumn{2}{|c|}{ Boys ( $n$ 1037) } & \multicolumn{2}{|c|}{ Girls (n 1278) } & \multicolumn{2}{|c|}{ Total $(n$ 2315) } \\
\hline & Mean & SD & Mean & SD & Mean & SD \\
\hline Age (years) & $10 \cdot 91$ & $0 \cdot 75$ & $10 \cdot 84$ & 0.73 & $10 \cdot 87$ & 0.73 \\
\hline BMI $\left(\mathrm{kg} / \mathrm{m}^{2}\right)$ & $20 \cdot 47$ & 3.97 & $20 \cdot 18$ & $3 \cdot 74$ & $20 \cdot 31$ & $3 \cdot 85$ \\
\hline \multirow[t]{2}{*}{ Waist circumference $(\mathrm{cm})$} & $70 \cdot 50$ & $10 \cdot 23$ & $67 \cdot 97$ & $9 \cdot 43$ & $69 \cdot 11$ & $9 \cdot 88$ \\
\hline & $n$ & $\%$ & $n$ & $\%$ & $n$ & $\%$ \\
\hline Normal weight & 595 & $57 \cdot 4$ & 786 & $61 \cdot 5$ & 1381 & $59 \cdot 7$ \\
\hline Overweight & 306 & $29 \cdot 5$ & 377 & $29 \cdot 5$ & 683 & $29 \cdot 5$ \\
\hline Obese & 136 & $13 \cdot 1$ & 115 & $9 \cdot 0$ & 251 & $10 \cdot 8$ \\
\hline
\end{tabular}


Table 2 Comparison of normal-weight and overweight/obese schoolchildren in relation to socio-economic and demographic factors and obesity status of the parents: nationwide sample of primary-school children aged 10-12 years, GRECO (Greek Childhood Obesity) study, October-May 2009

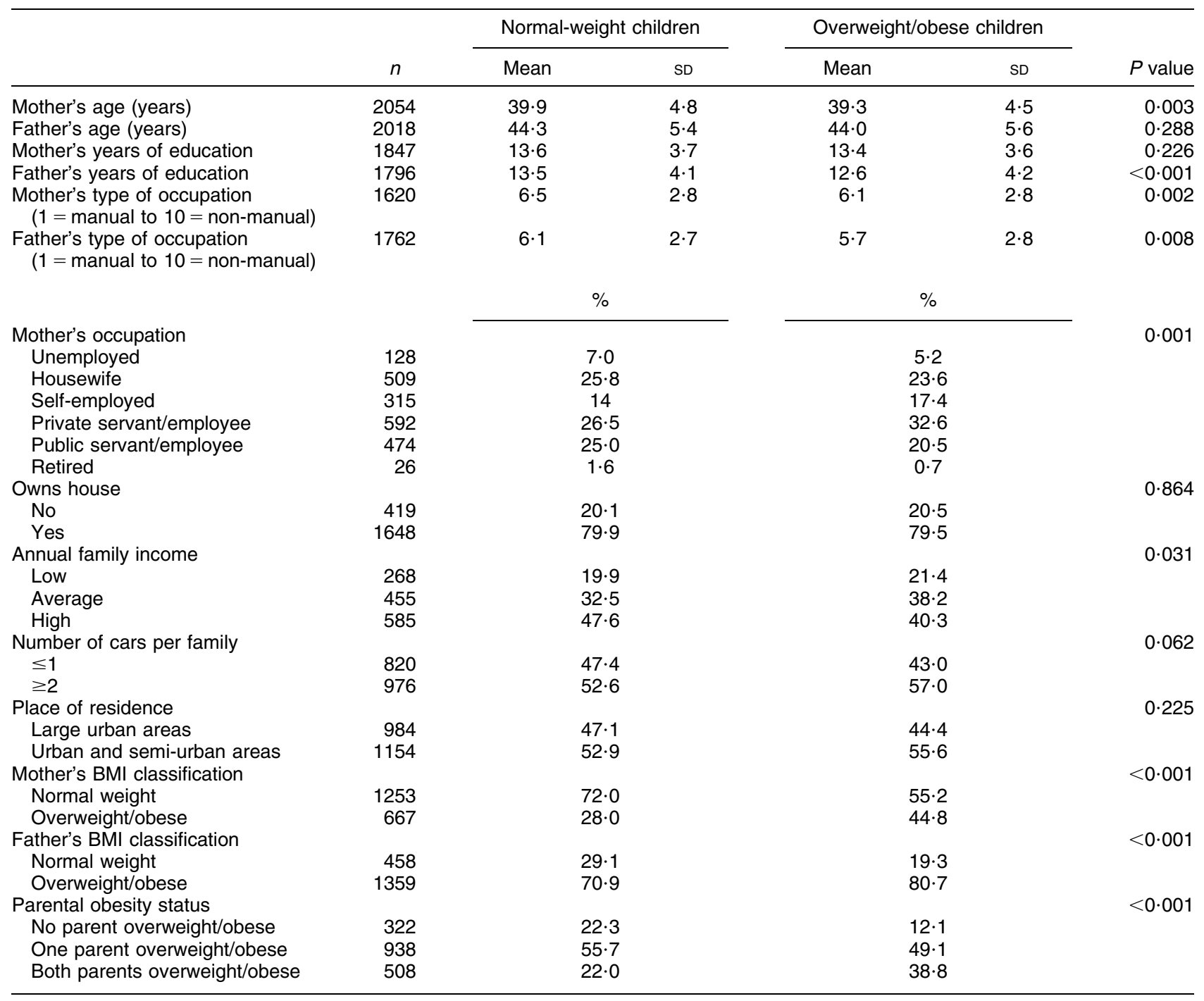

Regarding the physical activity levels of the parents, $40 \%$ of the fathers and $42 \%$ of the mothers were considered as physically active. Differences regarding the categorization of the parents according to their physical activity levels and the prevalence of overweight/obesity in their children were observed only for the fathers $\left(\chi^{2}=7 \cdot 14, P=0 \cdot 008\right)$. Specifically, for the overweight/obese children, $63 \%$ of their fathers were categorized as not physically active, in comparison to $57 \%$ of the fathers of normal-weight children. In addition, regarding the frequency of fathers' or mothers' physical activity together with their children, there were no differences regarding the prevalence of overweight/ obese children $\left(\chi^{2}=0 \cdot 08, P=0.99\right.$ and $\chi^{2}=4 \cdot 9, P=0 \cdot 17$, respectively; data not shown in tables). Concerning the frequency of meals 'out of home' no differences were observed between normal-weight and overweight/obese children even after adjusting for children's gender $(P>0.05$ for all; data not shown in tables). In addition, no differences were observed in the distribution of frequency of meal consumption with the whole family with respect to overweight/obesity prevalence $(P>0.05$ for all; data not shown in tables).

Unadjusted logistic regression models were used to evaluate the effect of selected sociodemographic characteristics on the likelihood of child overweight/obesity. From the aforementioned factors, mother's age, mother's and father's type of occupation, mother's profession, father's educational level and parental obesity status were significant predictors of children's overweight/obesity status. More specifically, a 1 year increase in mother's age reduced the odds for child overweight/obesity by approximately $3 \%(\mathrm{OR}=0.97,95 \% \mathrm{CI} 0.95,0.99)$. In addition, the odds of being an overweight/obese child were reduced when the mother's or father's type of occupation tended to be non-manual $(\mathrm{OR}=0.94,95 \%$ CI $0.91,0.98$ and $\mathrm{OR}=0 \cdot 95,95 \%$ CI $0 \cdot 92,0 \cdot 98$, respectively). The same 
Table 3 Results from logistic regression analysis to evaluate the main effect of various socio-economic and demographic characteristics of parents on the likelihood of childhood overweight/obesity, stratified by gender: nationwide sample of primary-school children aged 10-12 years, GRECO (Greek Childhood Obesity) study, October-May 2009

\begin{tabular}{|c|c|c|c|c|}
\hline & \multicolumn{2}{|c|}{ Girls } & \multicolumn{2}{|c|}{ Boys } \\
\hline & OR & $95 \% \mathrm{Cl}$ & OR & $95 \% \mathrm{Cl}$ \\
\hline Child's age (years) & $1 \cdot 00$ & $0 \cdot 77,1 \cdot 29$ & $0 \cdot 77$ & $0.59,1.00$ \\
\hline Mother's age (years) & 0.94 & $0.90,0.99$ & 0.95 & $0.91,0.99$ \\
\hline Father's type of occupation ( $1=$ manual to $10=$ non-manual) & $0 \cdot 91$ & $0.83,0.99$ & $1 \cdot 01$ & $0.92,1 \cdot 10$ \\
\hline Father's years of education & $1 \cdot 00$ & $0.94,1.05$ & 0.98 & $0.92,1.03$ \\
\hline \multicolumn{5}{|l|}{ Place of residence } \\
\hline Large urban areas & \multicolumn{4}{|c|}{ Reference category } \\
\hline Urban and semi-urban areas & $1 \cdot 01$ & $0 \cdot 69,1 \cdot 47$ & $1 \cdot 64$ & $1 \cdot 12,2 \cdot 40$ \\
\hline \multicolumn{5}{|l|}{ Family income } \\
\hline Low & \multicolumn{4}{|c|}{ Reference category } \\
\hline Average & $2 \cdot 14$ & $1 \cdot 21,3 \cdot 78$ & 0.91 & $0.52,1.60$ \\
\hline High & $1 \cdot 60$ & $0.87,2.93$ & 0.96 & $0.53,1.72$ \\
\hline \multicolumn{5}{|l|}{ Parental BMI classification } \\
\hline No parent overweight/obese & \multicolumn{4}{|c|}{ Reference category } \\
\hline One parent overweight/obese & 1.92 & $1 \cdot 09,3 \cdot 39$ & $1 \cdot 20$ & $0.73,1.98$ \\
\hline Both parents overweight/obese & $4 \cdot 13$ & $2 \cdot 25,7 \cdot 56$ & $2 \cdot 66$ & $1 \cdot 50,4 \cdot 71$ \\
\hline
\end{tabular}

effect (i.e. decreased odds of being overweight/obese) was also noticed regarding father's high educational status $(\mathrm{OR}=0.95,95 \%$ CI $0.93,0.97)$. Moreover, two types of mother's profession (i.e. private servants/employees and self-employed) were significant predictors of children's overweight/obesity status. Finally, parental obesity status was shown to be a significant predictor of childhood overweight/obesity: when one parent was overweight/ obese the odds of having an overweight/obese child were $1 \cdot 62$ (95\% CI $1 \cdot 22,2 \cdot 14)$ times higher as compared with normal-weight parents. Furthermore, the odds of being an overweight/obese child were threefold higher when both parents were overweight/obese as compared with normal-weight parents (OR $=3 \cdot 24,95 \%$ CI 2.39, 4.38). However, when these factors that were considered significant for developing overweight/obesity during childhood were evaluated together, adjusted for children's age and gender, only mother's age and parental obesity status (either one parent or both parents overweight/obese) were significant predictors for childhood overweight/obesity status (data not shown in tables). When the analysis was further performed stratified by children's gender, results revealed that mother's age was a protective predictor of both girls' and boys' obesity status, while parental obesity status had a positive effect on the likelihood of being an overweight/ obese child. Additionally, father's type of occupation was found to be negatively related to the prevalence of overweight/obesity among girls, while the residence in urban plus semi-urban areas was also positively related to the prevalence of overweight/obesity among boys (Table 3).

\section{Discussion}

The present nationwide study is the first in Greece to examine associations between several socio-economic and demographic factors and obesity status among children.
A recent review of cross-sectional studies published between 1990 and 2005 found that SES was inversely associated with children's overweight or obesity in $42 \%$ of the reviewed studies, with the rest of the studies reporting a mixture of inverse or no associations ${ }^{(5)}$. The choice of SES variable obviously influenced these relationships, with the evidence being less conclusive when using family income as a possible variable explaining childhood obesity, while parental education showed the most consistent inverse relationship with children's obesity risk. In addition, studies examining secular trends in the effect of SES factors from childhood to adulthood have revealed a particularly important effect of SES during childhood on obesity status in $\operatorname{adulthood}^{(8)}$.

According to the results of the present study, family income, the number of cars owned and house ownership did not seem to be related to the likelihood for children to be overweight or obese both at the bivariate level and in the multiple regression analysis performed. In contrast, the type of occupation of the parents, evaluated via a 10-point scale from unskilled (manual workers (lower values)) to executive (skilled workers (higher values)), which is considered indicative of social class ${ }^{(9)}$ and family financial and educational status ${ }^{(10)}$, did seem to affect the likelihood of having an overweight or obese child. However, we have to remark that the number of parental questionnaires with data concerning annual family income was smaller compared with the rest of the data provided, which may have introduced respondent bias from higher SES groups (Table 2).

In addition, paternal but not maternal education level seemed to be an important protective factor for childhood obesity, when analysed at the bivariate level. As reported in the literature, the most important sociodemographic factor explaining children's obesity status is parental education level, which is consistently inversely associated with children's body weight and adiposity ${ }^{(5,11)}$. Our results are 
reflective of such a relationship, suggesting that the level of education of the father is more likely to influence beliefs, knowledge on nutrition and health behaviours of the family, which in turn are involved in weight control through better nutritional and physical activity habits of the children $^{(5,12-14)}$.

Although maternal education level did not seem to influence the odds for overweight/obesity, an interesting finding of our study was that maternal profession appeared to influence the likelihood of the child being overweight/ obese at the bivariate level. One possible explanation for the finding that children whose mothers were private servants/employees or self-employed had greater rates of overweight/obesity than children whose mothers were unemployed, housewives or public servants/employees is the possible difference in work hours. Although we did not specifically assess the hours of daily work of the parents, it could be hypothesized that self-employed and private employees in Greece have longer work schedules, keeping them outside the home. This is probably associated with the time dedicated to nutritional guidance and education of the child, as well as both the quality and quantity of the child's diet ${ }^{(15-17)}$.

However, when the aforementioned factors that were considered significant for developing overweight/obesity during childhood at the bivariate level were evaluated together with other parameters, adjusted for children's age and gender, only mother's age and parental obesity status (either one parent or both parents overweight/obese) were significant predictors for childhood overweight/ obesity status (data not shown in tables). When the analysis was further stratified by children's gender, results revealed that mother's age was a protective predictor for both girls' and boys' overweight/obesity status, while parents' obesity status had a positive effect on the likelihood of being an overweight/obese child (Table 3). Additionally, father's type of occupation was found to be related to the prevalence of overweight/obesity among girls, and particularly the odds of a female child being overweight/obese were reduced when the father's type of occupation tended to be less manual. The finding that the rural area of residence was positively related to the prevalence of overweight/obesity among boys was not shown in the analysis of the whole children's sample ${ }^{(3)}$; nor has it been verified in previous cross-sectional studies in Greece where no differences were shown in the prevalence of overweight/obesity between children from different geographical areas (urban, semi-urban, rural areas) ${ }^{(18,19)}$.

The finding that the odds of developing overweight/ obesity decreases with increasing maternal age could be partly explained by the notion that individual and as a consequence family health awareness is higher in mothers of advanced age. Although not many well-organized antiobesity health policy interventions have taken place in Greece in recent years, there is extensive media attention to issues around obesity (diet and physical activity).
Therefore it is possible that older mothers respond more actively to media health-related messages or seek guidance from health professionals. These results are consistent with the idea that mothers have the same if not greater influence than fathers on children's behaviours and often hold the role of the head of the household. Another possible explanation could be that older mothers to a lesser extent misclassify their children's weight status as being lower than actual, an ability which is an important determinant of a child's healthy body weight development ${ }^{(20)}$. However, in a recent publication examining maternal perceptions of pre-school children's weight status, mother's age did not seem to affect the ability to classify children's weight status correctly ${ }^{(20)}$.

The present study also demonstrates that parental obesity status seems to be a highly influential factor on children's obesity status. Particularly when both parents were overweight/obese, the likelihood of male and female children to be overweight/obese was 2.66 and 4.13 times greater, respectively, than when children had no parent overweight/obese. An influence of parental obesity has been shown in many studies ${ }^{(21-23)}$ and may be explained by genetic as well as environmental and behavioural factors since parents play a direct role in shaping children's eating and activity habits ${ }^{(24,25)}$. In a recent study performed in Greece (Crete) it was also shown that parental BMI status had the greatest effect on children's BMI classification, as children with two obese parents had 11.6 times higher likelihood of being overweight or obese than their peers with normal-weight parents ${ }^{(26)}$. These findings were confirmed in another study of Greek pre-school children, in which children with one obese parent had $91 \%$ greater odds for being overweight than those with no obese parent, while the likelihood for being overweight was $2 \cdot 38$ times greater for children with two obese parents ${ }^{(27)}$. Children learn about eating not only through their own experiences but also by watching others, and especially their parents, who act as role models. A growing body of research demonstrates similarities between parents' and children's food acceptance, preferences and intake ${ }^{(15)}$.

The main strength of our study is the nationwide and relatively large sample of schoolchildren aged 10-12 years. Additionally, overweight and obesity rates of the children were estimated with direct anthropometric measurements, allowing us to estimate overweight and obesity prevalences and assess the contribution of several SES factors in overweight and obesity variance. An important limitation that has to be acknowledged is that the age range of the study population, which was late childhood and pre-adolescence, does not cover all age sections and that we have not assessed the pubertal status of the children. Puberty, in particular, is a period of rapid growth in which boys and girls increase fat-free mass substantially, and in girls is associated with considerable increase in body weight and body fat mass; therefore 
adolescence could be a critical period for developing obesity $^{(28)}$. It is in our future plans to proceed to conduct school-based childhood obesity prevention programmes. It has been suggested that these kinds of programmes should target 10-14-year-old children, since it has been demonstrated that prevention trials including older children have positive outcomes in terms of reducing $\mathrm{BMI}^{(29)}$. Another important limitation is the low response rate of the parental questionnaires, which may have introduced respondent bias from lower SES groups that are more likely to be either non-responders in survey research and overweight or obese ${ }^{(30)}$. However, in order to check for any bias regarding the data analysis of the sample of children used in the present study compared with the children for whom we did not obtain parental information, we compared the BMI of the two groups and found no differences. In addition, parental self-reported anthropometric values, although they may have some errors, are considered valid in identifying relationships in epidemiological studies, as when investigating associations with sociodemographic factors ${ }^{(31)}$. Finally, because the study had a cross-sectional design, it provides only evidence valuable for future investigations, but no definitive conclusions on causality.

\section{Conclusions}

The present study shows that the alarming magnitude of the paediatric obesity problem in all areas and regions of Greece $^{(3)}$ is associated with several socio-economic and demographic factors. The major sociodemographic determinants for childhood obesity in Greek children that retained statistical significance in the final multivariate model seem to be parental overweight, mother's age and father's type of profession.

Taking into account recent studies suggesting that childhood obesity in most cases tracks into adulthood ${ }^{(32,33)}$, the current findings are indicating an increased likelihood or even higher rates of obesity in adolescence and adulthood in the near future, exceeding those currently reported for the Greek adult population ${ }^{(19,34)}$. The data from the present survey stress the emerging need for preventive measures and anti-obesity health policy interventions that have to address to the parents and promote their active involvement, to effectively confront the paediatric obesity epidemic.

\section{Acknowledgements}

Sources of funding: Funding for the study was provided by the General Secretariat of Consumers-Greek Ministry of Development, the Hellenic Association of Food and Beverage Companies, Coca Cola Hellas, Coca Cola Hellenic Bottling Company, Cereal Partners Hellas, FAGE SA, Unilever Hellas, Nestlé Hellas and Kraft Foods Hellas.
This research was also co-financed by the European Union (European Social Fund - ESF) and Greek national funds through the Operational Program 'Education and Lifelong Learning' of the National Strategic Reference Framework (NSRF) - Research Funding Program: 'Heracleitus II. Investing in knowledge society through the European Social Fund'. Conflict of interest: The authors declare no conflict of interest. Author's contributions: P.F., D.B.P., G.R. and A.Z. were responsible for the study design and the supervision of the field study. D.B.P. and V.B. were responsible for the statistical analysis. P.F., D.B.P., N.V., G.R. and A.Z. were responsible for the interpretation of the data. All authors carried out data collection or data management, contributed to database preparation and participated in writing the final version of the submitted manuscript. Acknowledgements: The authors would like to thank the field investigators of the GRECO study: Aggeliki Birba, Ourania Brella, Zacharoula Giannari, Sotirio Kalamara, Antonia Kanella, Krini Konstantinou, Gioula Likakou, Olga Malisova, Konstantina Marouda, Alexandra Papadatou, Ivi Papaioannou, Eirini Papaisidorou, Olga Tsiotsiou and Niko Voutzouraki. Special thanks go to Dimitra Tzima for her invaluable secretarial help. The authors also wish to thank Dimitrio Bertzeleto and Panagioti Varagianni for their assistance during the study; and extend warm thanks to all the children and their families throughout the country who participated in this study, as well as to all the teachers who helped to carry out the study during school hours.

\section{References}

1. Lissau I, Overpeck MD, Ruan WJ et al.; Health Behaviour in School-aged Children Obesity Working Group (2004) Body mass index and overweight in adolescents in 13 European countries, Israel, and the United States. Arch Pediatr Adolesc Med 158, 27-33.

2. Lobstein T \& Frelut ML (2003) Prevalence of overweight among children in Europe. Obes Rev 4, 195-200.

3. Farajian P, Risvas G, Karasouli K et al. (2011) Very high childhood obesity prevalence and low adherence rates to the Mediterranean diet in Greek children: the GRECO study. Atherosclerosis 217, 525-530.

4. James WP, Nelson M, Ralph A et al. (1997) Socioeconomic determinants of health. The contribution of nutrition to inequalities in health. BMJ 314, 1545-1549.

5. Shrewsbury V \& Wardle J (2008) Socioeconomic status and adiposity in childhood: a systematic review of cross-sectional studies 1990-2005. Obesity (Silver Spring) 16, 275-284.

6. Cole TJ, Bellizzi MC, Flegal KM et al. (2000) Establishing a standard definition for child overweight and obesity worldwide: international survey. BMJ 320, 1240-1243.

7. World Health Organization (1997) Obesity: Preventing and Managing the Global Epidemic. Report of a WHO Consultation on Obesity. WHO Technical Report Series no. 894. Geneva: WHO.

8. Parsons TJ, Power C, Logan S et al. (1999) Childhood predictors of adult obesity: a systematic review. Int J Obes Relat Metab Disord 23, Suppl. 8, S1-S107.

9. Hart C, McConnachie A, Upton M et al. (2008) Risk factors in the Midspan family study by social class in childhood and adulthood. Int J Epidemiol 37, 604-614. 
10. Lioret S, Touvier M, Dubuisson C et al. (2009) Trends in child overweight rates and energy intake in France from 1999 to 2007: relationships with socioeconomic status. Obesity (Silver Spring) 17, 1092-1100.

11. Lamerz A, Kuepper-Nybelen J, Wehle C et al. (2005) Social class, parental education, and obesity prevalence in a study of six-year-old children in Germany. Int J Obes (Lond) 29 , 373-380.

12. Sobal J (1991) Obesity and socioeconomic status: a framework for examining relationships between physical and social variables. Med Anthropol 13, 231-247.

13. Liberatos P, Link BG \& Kelsey JL (1988) The measurement of social class in epidemiology. Epidemiol Rev 10, 87-121.

14. van Jaarsveld $\mathrm{CH}$, Miles A \& Wardle J (2007) Pathways from deprivation to health differed between individual and neighbourhood-based indices. J Clin Epidemiol 60, 712-719.

15. Patrick H \& Nicklas TA (2005) A review of family and social determinants of children's eating patterns and diet quality. $J$ Am Coll Nutr 24, 83-92.

16. Gable S, Chang Y \& Krull JL (2007) Television watching and frequency of family meals are predictive of overweight onset and persistence in a national sample of school-aged children. J Am Diet Assoc 107, 53-61.

17. Mamun AA, O'Callaghan MJ, Cramb SM et al. (2009) Childhood behavioral problems predict young adults' BMI and obesity: evidence from a birth cohort study. Obesity (Silver Spring) 17, 761-766.

18. Georgiadis G \& Nassis GP (2007) Prevalence of overweight and obesity in a national representative sample of Greek children and adolescents. Eur J Clin Nutr 61, 1072-1074.

19. Tzotzas T, Kapantais E, Tziomalos K et al. (2008) Epidemiological survey for the prevalence of overweight and abdominal obesity in Greek adolescents. Obesity (Silver Spring) 16, 1718-1722.

20. Manios Y, Kondaki K, Kourlaba G et al. (2009) Maternal perceptions of their child's weight status: the GENESIS study. Public Health Nutr 12, 1099-1105.

21. Kunesova M, Vignerova J, Steflová A et al. (2007) Obesity of Czech children and adolescents: relation to parental obesity and socioeconomic factors. J Public Health 15, 163-170.

22. Padez C, Mourao I, Moreira P et al. (2005) Prevalence and risk factors for overweight and obesity in Portuguese children. Acta Paediatr 94, 1550-1557.
23. Savva SC, Kourides Y, Tornaritis M et al. (2002) Obesity in children and adolescents in Cyprus. Prevalence and predisposing factors. Int J Obes Relat Metab Disord 26, 1036-1045.

24. Reilly JJ, Armstrong J, Dorosty AR et al. (2005) Early life risk factors for obesity in childhood: cohort study. BMJ 330, $1357-1364$.

25. Wardle J, Carnell S, Haworth CMA et al. (2008) Evidence for a strong genetic influence on childhood adiposity despite the force of the obesogenic environment. Am J Clin Nutr 87, 398-404.

26. Manios Y, Angelopoulos PD, Kourlaba G et al. (2010) Prevalence of obesity and body mass index correlates in a representative sample of Cretan school children. Int $J$ Pediatr Obes 6, 135-141.

27. Manios Y, Costarelli V, Kolotourou M et al. (2007) Prevalence of obesity in preschool Greek children, in relation to parental characteristics and region of residence. BMC Public Health 7, 178.

28. Dietz WH (1994) Critical periods in childhood for the development of obesity. Am J Clin Nutr 59, 955-959.

29. Kropski JA, Keckley PH \& Jensen GL (2008) School-based obesity prevention programs: an evidence based review. Obesity (Silver Spring) 16, 1009-1018.

30. Turrell G, Patterson C, Oldenburg B et al. (2002) The socioeconomic patterning of survey participation and nonresponse error in a multi-level study of food purchasing behaviour: area and individual level characteristics. Public Health Nutr 6, 181-189.

31. Spencer EA, Appleby PN, Davey GK et al. (2002) Validity of self-reported height and weight in 4808 EPIC-Oxford participants. Public Health Nutr 5, 561-565.

32. Field AE, Cook NR \& Gillman MW (2005) Weight status in childhood as a predictor of becoming overweight or hypertensive in early adulthood. Obes Res $\mathbf{1 3}$, 163-169.

33. Freedman DS, Khan LK, Serdula MK et al. (2004) Interrelationships among childhood BMI, childhood height, and adult obesity: the Bogalusa Heart Study. Int J Obes Relat Metab Disord 28, 10-16.

34. Panagiotakos DB, Pitsavos C, Chrysohoou C et al. (2004) Epidemiology of overweight and obesity in a Greek adult population: the ATTICA Study. Obes Res 12, 1914-1920. 